\title{
GÊNERO E FEMINISMO NO BRASIL UMA ANÁLISE DA REVISTA ESTUDOS FEMINISTAS
}

\author{
DEBORA DINIZ \\ Universidade de Brasília
}

PAULA FOLTRAN

ANIS: Instituto de Bioética, Direitos Humanos e Gênero

\begin{abstract}
Resumo A Revista Estudos Feministas (REF) é uma das mais importantes publicações sobre gênero e feminismo no Brasil. Este artigo descreve o perfil das autoras e dos temas dos artigos publicados na REF de 1992 até 2002. Foram analisados os títulos, os resumos e as palavras-chaves dos artigos avulsos e os temas dos dossiês, em um total de 20 editoriais, 105 artigos avulsos e 20 dossiês. A classificação e indexação temática do material seguiram o vocabulário controlado do "Tesauro para Estudos de Gênero e sobre Mulheres", da Fundação Carlos Chagas. Os resultados da análise mostram que $95 \%$ das autoras são mulheres e que $54 \%$ são oriundos das Ciências Sociais. Há artigos em todas as áreas temáticas previstas no Tesauro, exceto em "Ciência e Tecnologia" e "Educação", havendo uma concentração de publicações nas áreas temáticas "Ciências Sociais e Cultura" (26\%), "Linguagem, Literatura, Religião e Filosofia" (17\%) e "História e Mudança Social" (17\%). Os assuntos mais discutidos foram nesta ordem: divisão sexual do trabalho, análise literária, reprodução e teoria feminista. A análise mostra ainda que o trabalho de pesquisa em gênero e feminismo é solitário, havendo poucos artigos em co-autoria (12\%) e a metodologia de pesquisa preferencial é a qualitativa, em $92 \%$. A freqüência com que a mesma autora publica na REF é bastante baixa, havendo uma alta rotatividade de autoras. . A expectativa é que os resultados desta análise facilitem a definição de prioridades temáticas, favoreçam a criação de estratégias de pesquisa em áreas pouco exploradas, cooperando para a consolidação do trabalho educativo e político da revista, o que fortalecerá os estudos e pesquisas em gênero e feminismo no Brasil.
\end{abstract}

Palavras-Chave: gênero; feminismo; Revista Estudos Feministas

\section{Introdução'}

A Revista Estudos Feministas (REF) é uma das mais importantes no campo dos estudos de gênero e do feminismo na América Latina. ${ }^{2}$ Criada em 1992 como parte de uma estratégia deliberada para fortalecer os estudos feministas e de gênero no Brasil, atualmente, a REF conta com dez indexadores internacionais, e é reconhecidamente uma referência de grande prestígio entre pesquisadoras, professoras, estudantes e militantes de movimentos de mulheres interessadas na temática de gênero e feminismo no Brasil. ${ }^{3} \mathrm{~A}$ 
REF possui periodicidade quadrimestral, tendo publicado vinte e dois volumes, com uma média de 250 a 300 páginas cada um. Até 1998, a REF foi editada pela Universidade Federal do Rio de Janeiro, sendo transferida para a Universidade Federal de Santa Catarina, em 1999. Como conseqüência do processo de transferência, a periodicidade da REF foi temporariamente interrompida com apenas um volume no ano de 1999. No ano de 2003, foram confirmadas 290 assinaturas, sendo 49 de instituições nacionais e 15 internacionais, estas últimas em grande parte oriundas de universidades e centros de pesquisa nos Estados Unidos.

Este artigo descreve o perfil das pesquisadoras e dos temas de pesquisa em gênero e feminismo dos artigos publicados na REF desde sua criação. ${ }^{4}$ Para a classificação de conteúdo e indexação temática do material, foram analisados os títulos, os resumos e as palavras-chaves dos artigos avulsos e os assuntos dos dossiês. A classificação e indexação temática do material seguiram o vocabulário controlado do "Tesauro para Estudos de Gênero e sobre Mulheres", da Fundação Carlos Chagas. Foram ainda analisados os dados relativos à filiação institucional, distribuição regional e internacional das autoras, bem como a formação profissional das mesmas. ${ }^{5} \mathrm{~A}$ expectativa é que os resultados desta análise facilitem a definição de prioridades temáticas, favoreçam a criação de estratégias de pesquisa em áreas pouco exploradas, cooperando para a consolidação do trabalho educativo e político da REF, o que fortalecerá os estudos e pesquisas em gênero e feminismo no Brasil.

\section{Surgimento da REF}

A criação da $R E F$ foi resultado da maturidade das pesquisas em gênero nas universidades e da atuação dos movimentos de mulheres no Brasil. Cecília de Mello e Souza, em "Dos Estudos Populacionais à Saúde Reprodutiva", mostra como o "Concurso de Dotações para Pesquisa sobre a Mulher Brasileira", em 1978, promovido pela Fundação Carlos Chagas, exerceu um papel decisivo para o desenvolvimento da área. ${ }^{6}$ Foi também nesta época que surgiram os primeiros núcleos de pesquisa universitários sobre o tema da mulher e dos estudos de gênero no Brasil. Considera-se que o Núcleo de Estudos da Mulher (NEM), vinculado à PUC-RJ, instituído em 1980, tenha sido o primeiro núcleo universitário especializado nos estudos sobre a mulher. ${ }^{7}$

A REF foi oficialmente lançada em 1992, durante a reunião anual da Associação Nacional de Pós-Graduação e Pesquisa em Ciências Sociais (ANPOCS). Sua criação foi idealizada, em 1990, durante um seminário histórico que reuniu feministas e acadêmicas em uma cidade do interior do estado de São Paulo, onde além da revista, decidiu-se pela oferta de cursos itinerantes para fortalecer os estudos de gênero nas universidades brasileiras e a criação de um Tesauro em Gênero e Mulheres em Língua Portuguesa. ${ }^{8}$

O objetivo da REF era ser um instrumento educativo e político de difusão das pesquisas acadêmicas em gênero e feminismo, com a pretensão de ser também um veículo de formação para os movimentos de mulheres. ${ }^{9} \mathrm{O}$ primeiro editorial da revista, assinado por Lena Lavinas, dizia que "...a criação da REF, além de servir como canal de expressão dos movimentos de mulheres, pretende, antes de mais nada, difundir o conhecimento de ponta na área dos estudos feministas..." · Essa parceria da pesquisa com a intervenção social conformaria a identidade da revista, tendo sido reforçada nos editoriais subseqüentes.

O principal apoiador financeiro da revista foi a Fundação Ford, entidade também responsável pelo fortalecimento dos estudos de gênero e feminismo nas universidades brasileiras e uma das mais atuantes para a consolidação dos estudos e pesquisas no 
campo da saúde sexual e reprodutiva no país. ${ }^{10}$ Diferentemente de outros países latinoamericanos, onde a Fundação Ford também atuou, o Brasil foi o país que recebeu maior aporte financeiro neste campo, uma vinculação que imprimiu uma certa característica às pesquisas em gênero no Brasil, e à revista em particular. ${ }^{11}$

Desde sua criação, houve uma grande preocupação em garantir que a REF se manteria como um periódico de alto nível. Foi dispensado um esforço contínuo de vinculação da revista a importantes indexadores internacionais, como o Sociological Abstracts ou, mais recentemente, a SciELO (Scientific Library Online). ${ }^{12}$ Outra característica importante foi a política de internacionalização adotada: por um lado, traduziram-se artigoschave para o debate feminista e de gênero internacional, e, por outro, artigos nacionais foram também traduzidos para a língua inglesa, tendo havido inclusive um número especial neste idioma como forma de promover e divulgar a $R E F .{ }^{13}$ Atualmente, o tempo de espera para a publicação de um artigo, entre a submissão à $R E F$, avaliação das pareceristas, revisão dos originais, retorno à editoria e edição é de, em média, seis meses. ${ }^{14}$

\section{O Levantamento dos Dados}

A REF está estruturada em seis seções distintas. A primeira é o "Editorial”, um espaço aberto para as editoras expressarem opiniões, justificarem escolhas temáticas dos dossiês, além de referências a apoiadores e assinantes. A seção "Artigos" reflete o que há de ponta na pesquisa em gênero e feminismo no Brasil e internacionalmente, não havendo restrição de temas. Todos os artigos desta seção são submetidos à apreciação tanto por parte da editoria quanto por parte de pareceristas especializadas. A seção "Ponto de Vista" foi inicialmente criada como um espaço de debate de opiniões veiculadas em artigos, dossiês ou resenhas, no entanto, posteriormente, converteu-se na seção de entrevistas. A seção "Dossiê" apresenta artigos sobre uma temática específica, solicitados pela editoria da REF ou sugeridos por editoras convidadas. Assim sendo, tal seção embora também reflita o estado-da-arte da pesquisa em gênero e feminismo no Brasil, enfatiza a divulgação das ações e dos debates que ocorrem no âmbito dos movimentos feministas, contribuindo para promover novos temas. A seção "Ensaios" traz discussões sobre temas específicos baseadas em revisões da literatura. E por fim, a seção "Resenhas" apresenta discussões sobre livros recém-publicados no cenário nacional e internacional. ${ }^{15}$

Tendo em vista a forma como se organiza a REF e os objetivos deste artigo, foram selecionadas para a análise as seguintes seções dos volumes publicados de 1992 a 2002: ${ }^{16}$ (1) "Editorial", por ser um espaço de discussão das editoras, onde se resumem informações ou indicações pouco conhecidas, inclusive sobre o percurso histórico da REF; (2) "Artigos", por representar o que há de melhor e de mais ativo na demanda espontânea da pesquisa em gênero e feminismo no Brasil, sendo, por isso, um excelente indicativo sobre quais são os caminhos percorridos pela pesquisa de gênero e feminismo no país; ${ }^{17}$ (3) "Dossiês", por representar a ação induzida da revista, demonstrando quais temas a REF deseja promover, além de ser um espaço inicialmente pensado para ser destinado a publicação de estudos realizados por feministas militantes ou ligadas a movimentos sociais, mais do que de feministas acadêmicas.

Além do conteúdo dos artigos, também foram levados em conta os seguintes aspectos: (1) indexadores que a revista estava vinculada em cada número de edição, a fim de averiguar se houve ou não um avanço na profissionalização da comunicação científica; (2) os principais financiadores e apoiadores da revista, tendo em vista que a fonte de recursos pode ser um indicativo da agenda de pesquisas em gênero e feminismo no Brasil; (3) as editorias, para averiguar se o princípio da rotatividade editorial, estabelecido 
no primeiro número, foi mantido; (4) os detalhes na forma das edições, tais como número de páginas da revista e de cada artigo, além do número de artigos de cada volume; (5) informações sobre as autoras, tais como sexo, nacionalidade, filiação institucional, formação acadêmica, além de verificar qual tipo de autoria prevalece - se individual ou se coletiva - e o número de vezes que as autoras publicam na revista.

Foram estabelecidos dois tipos de cadastros para o controle das informações analisadas: (1) Cadastro do Volume: registro dos dados primários de cada volume, tais como, número de indexadores, apoiadores, números de páginas, um breve resumo do editorial, número de autoras, de artigos individuais e em grupo, tema do dossiê, ano e número da revista e (2) Cadastro do Artigo: registro dos dados referentes a cada artigo e autoria, tais como: número de páginas, ano e número da publicação, nome da(s) autora(s), formação, nacionalidade, instituição, título e resumo do artigo, área temática e termos específicos. ${ }^{18}$

Para a avaliação da formação de cada autora considerou-se tanto a graduação como a pós-graduação (mestrado ou doutorado), sempre que estas informações estivessem disponíveis na seção "Colaboradoras". Tendo em vista que a formação de graduação pode não representar as atuais preocupações e pesquisas de cada autora, foram especificadas as diferentes formações. No entanto, a coleta de dados revela que grande parte das autoras da REF possui uma formação contínua dentro de um determinado campo disciplinar, havendo pouca migração entre as áreas, o que reforça o significado da formação superior básica. O dado da filiação institucional foi considerado como a instituição a que a autora estava vinculada à época que escreveu o artigo, o que faz com que aquelas que escreveram mais de uma vez na REF e em anos diferentes sejam contabilizadas em duas instituições. O local de origem da pesquisadora é entendido, portanto, como o local de vinculação institucional da autora.

O cadastro do artigo, em especial a avaliação da área temática e dos assuntos à luz do vocabulário controlado do "Tesauro para Estudos de Gênero e sobre Mulheres", foi submetido a uma dupla avaliação independente, de forma a controlar grandes variações de interpretação. ${ }^{19}$ Quando houve divergência na avaliação, a análise foi submetida a uma terceira avaliação. Para a indexação do assunto de cada artigo foram analisados os títulos, resumos e palavras-chave. Dos 117 artigos publicados na REF neste período, apenas 105 foram considerados para esta pesquisa. ${ }^{20}$ Foram analisadas ainda as temáticas dos 20 dossiês. Os artigos dos dossiês não foram incluídos na análise.

Como estratégia complementar à análise do conteúdo das revistas, em especial para resgatar a história da criação da $R E F$, foram remetidos questionários de três perguntas abertas a todas as atuais editoras e ex-editoras. Como somente quatro pessoas, entre 14 ex-editoras e atuais editoras, responderam ao questionário, esses dados foram apenas perifericamente tratados nesta pesquisa. ${ }^{21}$

\section{Quem Publica em Gênero e Feminismo na REF}

A publicação em gênero e feminismo na REF é uma atividade eminentemente feminina: $95 \%$ das autoras da REF são mulheres. Dentre os poucos autores homens que publicaram artigos individuais na revista, a proporção é de quatro estrangeiros para um brasileiro, dado significativo que reflete a divisão sexual do trabalho em gênero e feminismo nas universidades e centros de pesquisa no Brasil. A mesma identidade de gênero se mantém nas instâncias decisórias da $R E F$, onde todas as coordenadoras, editoras e participantes do conselho editorial são mulheres. A REF conta com apenas dois homens no conselho consultivo internacional $(8 \%)$ e nenhum no conselho consultivo nacional. 
A seção de artigos avulsos é a parte mais nobre da revista. A média de artigos avulsos por revista é de cinco, o que torna o espaço bastante concorrido. ${ }^{22} \mathrm{~A}$ REF recebe uma oferta de artigos maior do que consegue absorver, sendo estimada uma recusa em torno de $48 \%$ do total de artigos submetidos à publicação. Diferentemente da seção dossiê, onde grande parte das autoras é convidada a participar, não há autoras convidadas na seção de artigos avulsos, exceto para os casos de tradução. Essa diferença de critérios faz com que a seção dos artigos avulsos seja a mais criteriosa e de maior notoriedade na revista.

Há uma grande participação de autoras estrangeiras, em especial estadunidenses (19\%) e francesas (8\%) na seção de artigos avulsos, um indicativo do diálogo teórico internacional considerado prioritário para o ensino e a pesquisa em gênero e feminismo no país. ${ }^{23}$ Autoras hispano-americanas (Argentina, Chile, Colômbia e México) somente estiveram presentes em $6 \%$ da revista e houve casos em que publicaram em parceria com autoras brasileiras. E, muito embora a proporção de autores homens estrangeiros seja maior do que autores brasileiros, não houve nenhum autor latino-americano dentre os estrangeiros. Brasil, França e Reino Unido foram os países de origem dos autores homens. Outro detalhe interessante é que, em geral, as autoras latino-americanas publicaram em língua espanhola, o que facilita a divulgação da $R E F$ na região. As publicações de autoria estrangeira foram responsáveis por $42 \%$ dos artigos avulsos da $R E F$, onde todos originalmente escritos em inglês, francês ou outro idioma foram traduzidos para a língua portuguesa e os originalmente em espanhol foram publicados neste idioma. ${ }^{24}$

A produção bibliográfica da REF é, em larga medida, uma atividade da região Sudeste do Brasil, responsável por $44 \%$ de todos os artigos publicados. Autoras da região Sul foram $9 \%$, da região Nordeste e Centro-Oeste foram $2 \%$ cada. ${ }^{25}$ Não houve nenhuma publicação na seção de "Artigos" de autoras da região Norte do Brasil na REF. Além desta distribuição desigual na produção do conhecimento sobre gênero e feminismo na REF, que pode ser um indicativo da má-distribuição dos incentivos à pesquisa no país, outro dado importante é a filiação institucional das autoras: $46 \%$ oriundas de universidades públicas (federais ou estaduais), $32 \%$ de universidades estrangeiras, ao passo que $7 \%$ de universidades privadas e apenas $3 \%$ de organizações não-governamentais. ${ }^{26}$

Uma outra característica marcante da publicação na REF é o fato de ser esta uma atividade solitária: $88 \%$ dos artigos foram de autoria individual. Há uma maior prevalência de artigos com mais de uma autoria entre os pesquisadores estrangeiros. ${ }^{27}$ Outro dado curioso é que a freqüência com que uma mesma autora publica repetidamente na REF é bastante baixa, havendo uma alta rotatividade de autoras. Apenas $6 \%$ das autoras publicaram mais de um artigo na REF, sendo que $38 \%$ delas faziam parte do conselho editorial nacional ou internacional por ocasião da publicação. Outro dado bastante significativo dos artigos analisados é a absoluta preferência por métodos qualitativos de levantamento de dados (etnografias ou entrevistas) ou por artigos de discussão teórica sem qualquer referência a dados empíricos, e que, somados, representaram $92 \%$ do universo analisado.

\section{O que se pesquisa em gênero e feminismo na REF}

A pesquisa em gênero e feminismo na REF é um campo consolidado nas Ciências Sociais: $28 \%$ das autoras da revista possuíam graduação em Antropologia, Sociologia ou Ciências Sociais e $34 \%$ possuíam pós-graduação (mestrado ou doutorado) nessas mesmas áreas. ${ }^{28}$ Os outros campos com maior incidência de publicações foram graduação (8\%) e pós-graduação em História (7\%) e graduação (4\%) e pós-graduação em Letras, Literatura ou Educação (8\%). ${ }^{29}$ 
Outras áreas internacionalmente consolidadas na pesquisa de gênero e feminismo, tais como Psicologia, Ciência Política, Filosofia, Direito e Serviço Social, participaram marginalmente da história da REF, com $4 \%, 3 \%, 2 \%, 1 \%$ e $1 \%$, respectivamente. Em números absolutos isso representa entre quatro e duas autoras de cada uma dessas últimas áreas na história da revista. Muito embora a publicação de artigos sobre questões relacionadas à saúde reprodutiva das mulheres tenha sido um assunto bastante discutido na REF, a participação de autoras de campos disciplinares da saúde foi tímida: $1 \%$ da Medicina e $1 \%$ da Biologia.

O "Tesauro para Estudos de Gênero e sobre Mulheres" propõe nove áreas temáticas: "Ciência e Tecnologia", "Ciências Naturais e Saúde", "Ciências Sociais e Cultura", "Comunicação, Artes e Espetáculos", "Economia e Emprego", "Educação", "História e Mudança Social", "Lei, Governo e Políticas Públicas" e "Linguagem, Literatura, Religião e Filosofia". Há publicações em todas as áreas do Tesauro, exceto em "Ciência e Tecnologia" e "Educação", havendo uma concentração de publicações nas áreas temáticas "Ciências Sociais e Cultura" (26\%), "Linguagem, Literatura, Religião e Filosofia" (17\%) e "História e Mudança Social" (17\%), o que, em larga medida, pode ser considerado uma conseqüência natural da formação profissional das autoras.

Somente de posse desse quadro de assuntos e áreas temáticas da revista é que se percebe a importância dos dossiês. Já foram publicados vinte dossiês, todos sobre assuntos variados, havendo, no entanto, uma concentração nas seguintes temáticas: saúde, reprodução e sexualidade (25\%); etnia (20\%); gênero (15\%); feminismo (15\%) e política (10\%). Os outros dossiês versaram sobre classe social, educação e meio ambiente, cada um com $5 \%$ do total. Os dossiês exercem um papel fundamental na história da REF. O tema da educação, da velhice, da violência e do meio ambiente são alguns desses exemplos: fora do dossiê, foram tratados marginalmente, em média, por apenas um artigo. Na verdade, o dossiê representa não apenas a articulação da revista com as demandas e necessidades dos movimentos sociais e de mulheres no Brasil, mas, principalmente, é um sinal da sensibilidade do conselho editorial para as ausências temáticas da pesquisa de gênero e feminismo no país: apenas $7 \%$ dos assuntos tratados nos dossiês foram discutidos pelos artigos avulsos, o que torna possível afirmar que se não fosse a ação induzida dos dossiês muitos temas ainda estariam ausentes da REF.

Uma característica do material analisado é a excessiva pulverização dos assuntos, chegando a $64 \%$ a ocorrência de publicação de um único artigo sobre determinado assunto. Os assuntos mais discutidos foram, nesta ordem: divisão sexual do trabalho, análise literária, reprodução e teoria feminista. Os temas da divisão sexual do trabalho e da reprodução estiverem presentes na história da $R E F$, sendo que o último, além de ter sido assunto constante dos artigos, foi também tema de dossiês, o mesmo não tendo ocorrido com o primeiro tema. A categoria divisão sexual do trabalho cobre artigos sobre trabalho feminino, mulheres nas Forças Armadas, domicílios chefiados por mulheres e mercado de trabalho, ao passo que a de reprodução inclui artigos sobre tecnologia reprodutiva, saúde reprodutiva, reprodução, AIDS e aborto. O tema da reprodução, muito embora não seja o de maior presença na revista, foi o que apresentou melhor distribuição no tempo, pois quase todos os volumes continham um artigo sobre o assunto.

\section{Considerações finais}

A análise do material nos permite afirmar que a produção bibliográfica da REF é resultado de atividades femininas, promovidas pelas principais universidades e centros de pesquisa do país, onde predominam as cientistas sociais com preferência por métodos 
qualitativos de pesquisa ou pela discussão teórica. Os principais assuntos discutidos foram divisão sexual do trabalho, análise literária, reprodução e teoria feminista. Há poucos homens autores no campo dos estudos de gênero e feminismo que publicaram na $R E F$, um claro indicativo da divisão sexual do campo no Brasil. Esses poucos que nela publicaram, o fizeram a partir de uma perspectiva das questões masculinas e sobre assuntos com um recorte de masculinidade. A produção bibliográfica na REF é ainda uma atividade solitária com poucos artigos resultantes do trabalho em equipe. Outra característica é o fortalecimento do diálogo internacional, em especial com autoras estadunidenses e francesas, havendo, no entanto, um parco intercâmbio com a América Latina.

Considerando que a REF é uma das publicações-chave sobre gênero e feminismo no Brasil e, certamente, uma das mais importantes na América Latina, os resultados encontrados podem ser bastante sugestivos sobre a agenda de publicações, assim como sobre a distribuição do trabalho intelectual sobre gênero e feminismo no Brasil. A expectativa é que os resultados desta análise, ao identificar os avanços teóricos e estruturais do campo, assim como ao pontuar as ausências do debate, fortaleçam as pesquisas e a produção intelectual sobre o tema no Brasil.

\section{Notas}

Copyright $\odot 2004$ by Revista Estudos Feministas.

' Agradecemos a gentileza da equipe da REF para com esta pesquisa, fornecendo dados e esclarecendo dúvidas, em especial à Carmem Vera Gonçalves Vieira Ramos, Cláudia de Lima Costa, Luzinete Simões Minella, Miriam Pillar Grossi e Rita Maria Xavier Machado. Agradecemos ainda a todas as ex-editoras e atuais editoras que participaram das entrevistas.

${ }^{2} \mathrm{O}$ uso do gênero feminino neste artigo justifica-se pelo fato da maioria absoluta das pesquisadoras em gênero e feminismo no Brasil serem mulheres. Este dado será adiante comprovado através do perfil de autores e autoras que publicaram na Revista Estudos Feministas (REF) desde sua criação. Somente será utilizado o gênero masculino para descrever a participação de homens, sendo utilizado o gênero feminino para o plural.

${ }^{3}$ Uma segunda revista que pode ser apontada como de grande prestígio e, portanto, também representativa dos estudos de gênero no Brasil é a Cadernos Pagu da Universidade Estadual de Campinas (Unicamp). A título complementar da análise da REF, a Cadernos Pagu também foi analisada e, quando pertinente, alguns dados serão indicados para demonstrar ora diferenças, ora permanências no campo de gênero e feminismo no Brasil. Adriana Piscitelli, lara Beleli e Maria Margaret Lopes, em "Cadernos Pagu: contribuindo para a consolidação de um campo de estudos", apresentam algumas análises e estatísticas sobre essa publicação. Dado que o desenho metodológico da pesquisa não foi o mesmo, não há como considerarmos diretamente os resultados apresentados (Estudos Feministas. Florianópolis, v. 11, n. 1, 2003. p. 242-6).

${ }^{4}$ Versões preliminares deste artigo foram discutidas no VI Encuentro de Centros y Programas de Estudios de la Mujer y de Género en Instituciones de Educación Superior de América Latina y el Caribe, realizado no México, e no I Encontro Internacional e II Encontro Nacional de Publicações Feministas, realizado em Florianópolis, ambos em 2003.

${ }^{5}$ Esses últimos dados foram igualmente coletados na Cadernos Pagu para fins comparativos, demonstrando que a configuração de ambas revistas é bastante semelhante.

${ }^{6}$ SOUZA, 2002

${ }^{7}$ MELLO e SOUZA, 2002

${ }^{8}$ BRUSCHINI, Cristina, 1998.

- COSTA, Claudia de Lima, em "As Publicações Feministas e a Política Transnacional da Tradução: reflexões do campo", mostra que a REF estabeleceu três objetivos como prioritários em sua fundação: ser um canal de expressão dos movimentos de mulheres; difundir o conhecimento de ponta na área dos estudos feministas e manter um compromisso com as demandas sociais da discussão feminista (Estudos Feministas. Florianópolis, v. 11, n.1, 2003, p.254-64)

${ }^{10}$ Muito embora um dos principais parceiros dos estudos e pesquisas em gênero e do movimento de mulheres no Brasil tenha sido o Programa de Saúde Sexual e Reprodutiva da Fundação Ford, o financiador da REF fol - Programa de Direitos Humanos. Além da Fundação Ford, vale registrar o papel desempenhado pela Fundação MacArthur no Brasil no campo dos estudos, pesquisas e intervenções em saúde e direitos reprodutivos. 
${ }^{11}$ Em entrevista a uma das ex-editoras da REF, um exemplo curioso desta interseção da dupla identidade da revista (pesquisa e fortalecimento dos movimentos de mulheres) com o aporte financeiro da Fundação Ford, foi a referência de que o próprio título da revista teria sido definido a partir daí: "...sobre o título com a categoria feminismo, e não gênero, há várias narrativas... Pelo que ouvi dizer o nome REF - em vez de estudos de gênero - foi dado de forma instrumental para conseguir financiamento da Fundação Ford, pois salientava a inserção da revista junto aos movimentos de mulheres no Brasil..." [a pergunta feita foi "por que a revista utiliza a categoria feminismo e não gênero em seu título?].

${ }^{12}$ Cadernos Pagu conseguiu seu primeiro indexador apenas sete anos depois de sua criação, muito depois da $R E F$, que foi indexada já em seu terceiro número, em 1993. Hoje, a REF consta em 10 indexadores, enquanto que Cadernos Pagu chegou a seis somente em 2003, com seu vigésimo número.

${ }^{13} \mathrm{Em} 1999$, houve um número especial em inglês.

${ }^{14}$ Segundo a atual editoria da REF, o tempo médio de espera é de seis meses, mas a depender do fluxo de artigos e da prontidão com que as autoras realizam as modificações após a avaliação do Conselho Editorial, este prazo pode variar de quatro a doze meses.

${ }^{15} \mathrm{Em}$ comparação com Cadernos Pagu , um ponto interessante a ser ressaltado é a inexistência de um padrão pré-definido de formatação da revista. Cada número do Pagu apresenta um formato diferente, no geral há uma seção de artigos, mas houve casos de números que não contam com essa seção (12,5\%). Apenas 37,5\% dos volumes apresentavam uma seção de Dossiês e 12,5\% de Debates, o que equivale à seção Ponto de Vista da REF. Outras seções existentes na Cadernos Pagu são: Resenhas (75\%), Documentos $(62,5 \%)$, Comentários $(6,25 \%)$ e Entrevistas $(6,25 \%)$. Além da falta de padrões no que se refere ao formato da revista, o número de artigos também apresenta uma variação muito grande, de dois a onze.

${ }^{16} \mathrm{De} 1992$ a 2002, foram publicados vinte e dois volumes. No entanto, como houve dois volumes especiais que não seguiam os padrões tradicionais da revista, os mesmos não foram incluídos para a análise deste artigo.

17 Os vinte volumes analisados continham 117 artigos. No entanto, 12 artigos não continham resumos e foram, por isso, considerados inválidos. No total foram analisados 105 artigos.

${ }^{18} \mathrm{Um}$ terceiro tipo de cadastro foi o Cadastro Geral/Pagu: registro dos dados primários de cada volume, dados referentes às autoras, tais como formação, filiação institucional e distribuição regional e internacional. 19 Durante a fase de análise de conteúdo dos artigos, o vocabulário controlado proposto pelo Tesauro foi, em alguns momentos, considerado insuficiente para cobrir alguns artigos. A despeito dessa limitação, optamos por adotá-lo na integralidade.

${ }^{20}$ Doze artigos não continham resumo.

${ }^{21}$ As sete pesquisadoras que lideraram a edição da REF no período considerado foram: Lena Lavinas; Maria Luiza Heilborn; Lena Lavinas e Ana Arruda Callado; Leila Linhares Barsted e Ana Arruda Callado; Claudia de Lima Costa e Miriam Pillar Grossi; Claudia de Lima Costa, Luzinete Simões Minella e Miriam Pillar Grossi; Claudia de Lima Costa e Luzinete Simões Minella; Luzinete Simões Minella.

${ }^{22}$ Há revistas que chegam a ter onze artigos avulsos, mas a média aritmética de artigos equivale a cinco. ${ }^{23}$ Nesse caso não foram considerados os países de origem das autoras, mas sua filiação institucional tendo em vista a influência que a tradição local exerce sobre o processo criativo de cada pesquisadora.

${ }^{24}$ Em linhas gerais, Cadernos Pagu apresenta uma distribuição regional bastante similar a da REF. A porcentagem de artigos de autoria estrangeira é de $32 \%$. Dentre as estrangeiras, mais uma vez as estadunidenses tomam a dianteira. Estas estão representadas por 17\% dos artigos. A novidade se configura no aparecimento de autoras portuguesas, que perfazem um total de $4 \%$, ao lado das francesas, com a mesma quantidade. As autoras hispano-americanas estão pouco representadas aqui também, onde aparecem com a porcentagem de 1,28\%. Foram analisados 16 volumes, num total de 76 artigos e 77 autoras.

${ }^{25} \mathrm{Na}$ verdade, o mais correto seria falar no Distrito Federal do que região Centro-Oeste, pois somente foram publicados artigos de autoras brasilienses. A mesma ressalva pode ser feita em relação à região Nordeste, pois somente foram publicados artigos do estado da Bahia.

${ }^{26} \mathrm{~A}$ REF e a Pagu apresentam grandes semelhanças quanto à distribuição regional. Na Cadernos Pagu, a região Sul e Sudeste estão representadas por $58 \%$ das autoras, sendo que a região Sudeste sozinha detem $53 \%$ das autoras e o restante $5 \%$ deste total, está representado pela região Sul. O Norte mais uma vez não aparece na Pagu e as regiões Nordeste e Centro-Oeste estão representadas marginalmente, com $2 \%$ e $3 \%$ respectivamente. Os principais centros de estudo e pesquisa do país estão privilegiados também na Cadernos Pagu, onde $46 \%$ das autoras estão filiadas a Universidades Públicas (estaduais ou federais), exatamente a mesma proporção encontrada na análise da REF. Na Pagu, dentre as universidades públicas do país, 33\% das autoras são da Unicamp, instituição-sede do Núcleo de Estudos e a revista Pagu. As universidades privadas quase não produziram textos para o periódico, estando presentes em apenas $3 \%$ do total..

${ }^{27}$ Fato que ocorre igualmente na Cadernos Pagu. Em toda história da revista houve apenas um artigo publicado em parceria. Vale lembrar que esta é uma análise da publicação no Brasil, e não fora dele, de 
modo que independente da forma como as autoras estrangeiras escrevam em seus próprios países, no Brasil elas privilegiam a parceria.

${ }^{28}$ Um número bastante próximo foi encontrado na Cadernos Pagu, onde $38 \%$ possuíam alguma formação, fosse ela Graduação, Mestrado ou Doutorado, nestas áreas. Os dados foram contabilizados juntos, porque a revista não especificava qual era o tipo de formação básica..

${ }^{29}$ Interessante notar que na Pagu a ordem se altera, de modo que depois de Ciências Sociais, a maior área é História (19\%). As demais formações são representadas por no máximo $4 \%$ das autoras. Um número considerável de autoras não identificou suas graduações, $23 \%$.

\section{Referências}

BELELI, lara; LOPES, Maria Margaret e PISCITELLI, Adriana. "Cadernos Pagu: contribuindo para a consolidação de um campo de estudos". Revista Estudos Feministas, v. 11 , n. 1, p. 242-6, jan-jun 2003.

BRUSCHINI, Cristina. "Apresentação". In: BRUSCHINI, Cristina; ARDAILLON, Danielle; UNBEHAUM, Sandra G. Tesauro para Estudos de Gênero e sobre Mulheres. São Paulo: Fundação Carlos Chagas/Ed. 34, 1998. p. 7-9.

COSTA, Claudia de Lima. "As publicações feministas e a política transnacional da tradução: reflexões do campo". Revista Estudos Feministas, v. 11, n. 1, p. 254-64, jan-jun 2003.

MELLO e SOUZA, Cecília de. "Dos Estudos Populacionais à Saúde Reprodutiva". In: BROOKE, Nigel; WITOSHYNSKY, Mary. Os 40 Anos da Fundação Ford no Brasil: uma parceria para a mudança social. São Paulo: EDUSP/Fundação Ford, 2002. p. 131-164.

\section{Gender and Feminist Studies in Brazil: An Analysis of Revista Estudos Feministas}

Abstract: Revista Estudos Feministas (REF) is one of the most important gender and feminist journals in Brazil. This article describes the author background and the subjects of the articles published in REF from 1992 to 2002. It was analysed the title, abstracts and keywords of the articles and the topics of the dossier, totalising 20 editorials, 105 articles and 20 dossiers. The classification and indexation of the material was guided by the controlled vocabulary of the "Tesauro para Estudos de Gênero e sobre Mulheres", from Fundação Carlos Chagas. The results show that $95 \%$ of the authors are women, and that $54 \%$ are from Socials Sciences. There are articles in all thematic areas suggested by the Tesauro except on "Science and Technology" and "Education", with a concentration on the following thematic areas: "Socials Sciences and Culture" (26\%), "Language, Literature, Religion and Philosophy" (17\%) and "History and Social Transformation" (17\%). The most discussed topics were in this order: sexual division of work, literary analysis, reproduction, and feminist theory. The analysis of REF suggests that gender and feminist research is a solitary activity, with a few number of articles published in partnership. There is a strong preference for qualitative methodologies (92\%). This article aims to facilitate the process of identification some marginal areas in the gender and feminist studies in Brazil, empowering the educational and political work of the journal.

Keywords: gender; feminism; Revista Estudos Feministas. 